\title{
The European Unemployment Dilemma
}

\author{
by \\ Lars Ljungqvist and Thomas J. Sargent*
}

May 1997

Post World War II European welfare states experienced several decades of relatively low unemployment, followed by a plague of persistently high unemployment since the 1980's. We impute the higher unemployment to welfare states' diminished ability to cope with more turbulent economic times, such as the ongoing restructuring from manufacturing to the service industry, adoption of new information technologies and a rapidly changing international economy. We use a general equilibrium search model where workers accumulate skills on the job and lose skills during unemployment.

* Ljungqvist: Stockholm School of Economics and Federal Reserve Bank of Chicago; Sargent: Hoover Institution, Stanford, and University of Chicago. We thank George Akerlof, Sherwin Rosen, Jose Scheinkman, two anonymous referees and seminar participants at various institutions for criticisms and suggestions. We are grateful to Cristina De Nardi, Juha Seppala and Christopher Sleet for excellent research assistance. The views expressed here are ours and not necessarily those of the Federal Reserve System. Sargent's research was supported by a grant to the National Bureau of Economic Research from the National Science Foundation. 


\section{Introduction}

During their first decades, European welfare states exhibited unemployment rates equal to or less than those of other market economies; but in the 1980's, they suffered large increases in unemployment, which have endured. Figure 1 shows that unemployment in European OECD countries has from 1983 persistently exceeded the OECD average by around two percentage points. Higher occurrences of long term unemployment have accompanied higher levels of unemployment. According to Table 1, more than half of all European unemployment in 1989 was classified as long-term unemployment with a duration of a year and over, up from less than a third of unemployment in $1979 .{ }^{1}$ Table 1 shows that the increasing incidence of long-term unemployment is common to the European

OECD countries. ${ }^{2}$ In contrast, the United States escaped such a persistent increase in unemployment, and U.S. long-term unemployment has remained low.

1 Sinfield (1968) provides a longer historical perspective on long-term unemployment in Europe. He studied it during the 1960's when, except for Belgium, it was not considered a major problem. Defining 'long-term' as six months and over, Sinfield concluded that long-term unemployment typically affected half a percent of a country's labor force. In countries such as former West Germany and the Scandinavian countries, it was less than two tenths of a percent.

2 A glaring exception in Table 1 to the European unemployment dilemma in the 1980 's is Sweden. Ljungqvist and Sargent (1995b) provide an explanation of the Swedish unemployment experience including the current crisis with more than 13 per cent of the labor force either unemployed or engaged in labor market programs. 


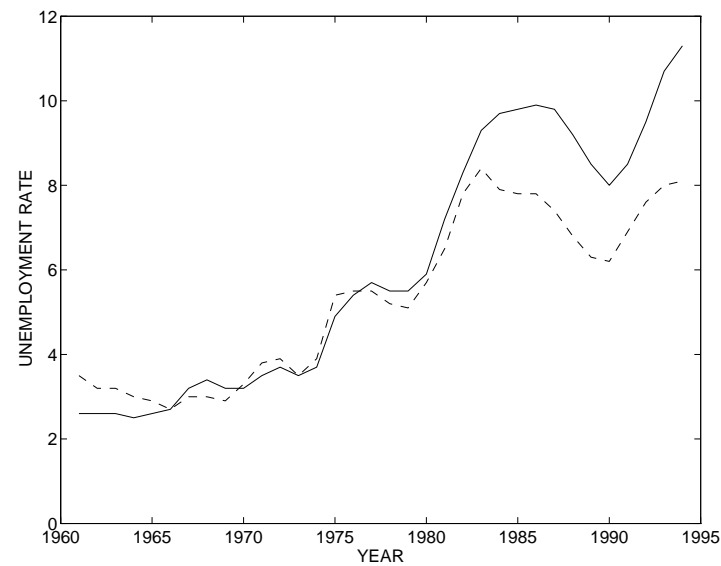

Figure 1. Unemployment rate in OECD as a per cent of the labor force. The solid line is unemployment in the European OECD countries and the dashed line is unemployment in the total OECD. Source: Data for 1961-1977 are from OECD (1984a), and data for 1978-1994 are from OECD (1995). 
Table 1: Unemployment and long-term unemployment in OECD

\section{Unemployment}

(Per cent)
Belgium

France

Germany $^{g}$

Netherlands

Spain

Sweden

United Kingdom

6.3

4.5

3.2

4.9

5.2

1.9

5.0

6.7

United States

OECD Europe

Total OECD
4.7

4.9
10.8

9.0

5.9

9.7

17.5

2.5

10.0

7.2

5.6

8.8

9.9

17.3

74.9

87.5

77.7

55.1

63.7

68.9

39.9

66.7

65.4

7.1

49.3

66.1

74.4

22.9

51.6

72.7

72.2

7.7

19.6

18.4

35.2

8.2

39.7

57.2

60.7
Long-term unemployment of six months and over (Per cent of total unemployment) $1979^{c} \quad 1989^{d} \quad 1995^{e}$

10.3

7.6

a) Unemployment in 1974-79 and 1980-89 is from OECD, Employment Outlook (1991), Table 2.7.

b) Unemployment in 1995 is from OECD, Employment Outlook (1996), Table 1.3.

c) Long-term unemployment in 1979 is from OECD, Employment Outlook (1984b), Table H.; except for the OECD aggregate figures that are averages for 1979 and 1980 from OECD, Employment Outlook (1991), Table 2.7. 
Table 1 (continued)

\section{Long-term unemployment}

of one year and over

(Per cent of total unemployment)

$1970^{f} \quad 1979^{c} \quad 1989^{d} \quad 1995^{e}$

Belgium

$\cdots$

58.0

76.3

62.4

France

22.0

30.3

43.9

45.6

Germany

8.8

19.9

49.0

48.3

Netherlands

12.2

27.1

49.9

43.2

Spain

27.5

58.5

56.5

Sweden

$\cdots$

6.8

6.5

15.7

United Kingdom

17.6

24.5

40.8

43.5

United States

$\begin{array}{ll}\ldots & 4.2\end{array}$

5.7

9.7

OECD Europe

$\begin{array}{ll}\cdots & 31.5\end{array}$

Total OECD

$\begin{array}{ll}\ldots & 26.6\end{array}$

52.8

33.7

d) Long-term unemployment in 1989 is from OECD, Employment Outlook (1992a), Table N.; except for the OECD aggregate figures that are from OECD, Employment Outlook (1991), Table 2.7.

e) Long-term unemployment in 1995 is from OECD, Employment Outlook (1996), Table Q.

f) Long-term unemployment in 1970 is from OECD, Employment Outlook (1983), Table 24.

g) Except for year 1995, data refer to former West Germany only. 
Various theories have been proposed to explain the rise in European unemployment. Blanchard and Summers (1986) and Lindbeck and Snower (1988) impute the outcome to "insider-outsider" conflicts between employed and unemployed workers that arose in the highly unionized economies of Europe. Bentolila and Bertola (1990) study the idea that excessive European hiring and firing costs contributed to higher unemployment. Malinvaud (1994) emphasizes a capital shortage in Europe caused by high real wages in the 1970's and high real interest rates in the 1980's. All these explanations assign the problem to the demand for labor, making the decisions either of employers or of unionized employed workers sustain a high unemployment rate. In contrast, we focus on the effects of the welfare state on the supply of labor. It is well known that high income taxation and generous welfare benefits distort workers' labor supply decisions. We hope to contribute a sense of how the welfare state adversely affects the dynamic responses to economic shocks and to increasing turbulence in the economic environment. ${ }^{3}$

One reason for the past lack of emphasis on workers' distorted incentives as an explanation for high European unemployment must be the scarce empirical support for the idea. As pointed out by OECD (1994a, chapter 8), most earlier empirical studies have failed to find any cross-country correlation between unemployment benefits and aggregate unemployment. In fact, there was even a negative correlation between benefit levels and unemployment in the 1960's and early 1970's. A common conclusion has therefore been that generous entitlement programs are not to be blamed for high unemployment rates. However, the same OECD study presents an opposing view and interprets the time-series evidence as indicating that unemployment rates do respond to benefit entitlements, but with a considerable lag of 5 to 10 years, and in some cases 10 to 20 years. A natural question then becomes, why are there such lags between rises in benefits and later sharp rises in unemployment? Our analysis suggests that the lags are purely coincidental, and that the real explanation for persistently higher European unemployment from the 1980's is to be found in a changed economic environment.

3 Our analysis will bear out the assertion by Layard, Nickell and Jackman (1991, page 62) that the "unconditional payment of benefits for an indefinite period is clearly a major cause of high European unemployment." However, our model differs sharply from their framework, which emphasizes hysteresis and nominal inertia in wage and price setting. 


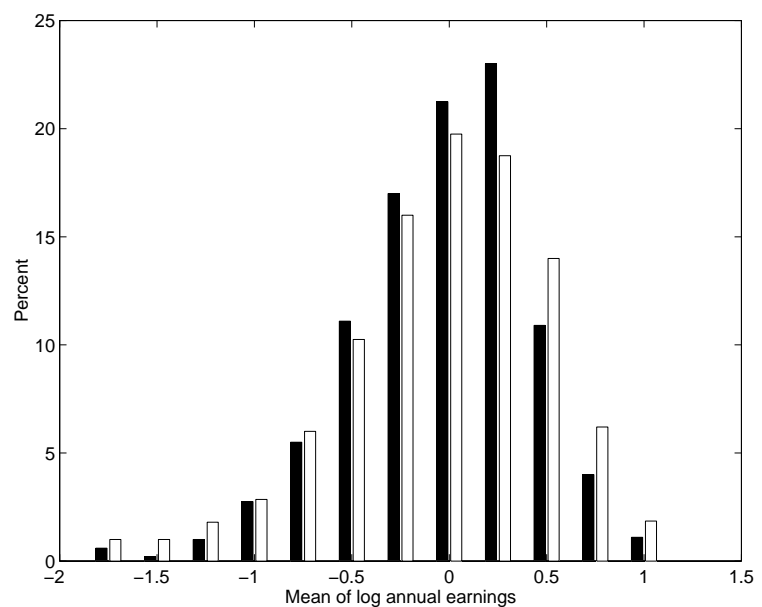

Figure 2a. Distribution of permanent earnings, 1970-78 and 1979-87. Reproduction of Gottschalk and Moffitt's (1994) Figure 2. The black bars correspond to $1970-78$, the white bars to $1979-87$.

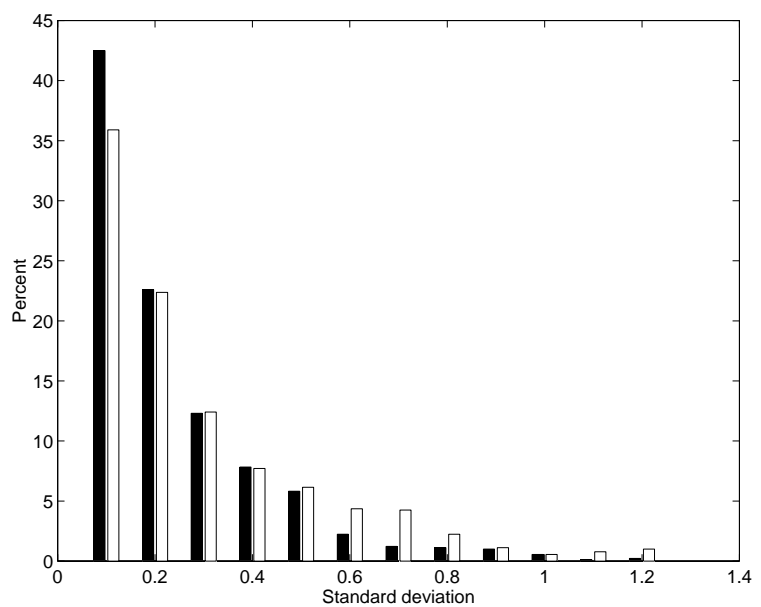

Figure 2b. Distribution of standard deviations of individuals' transitory earnings, $1970-78$ and 1979-87. Reproduction of Gottschalk and Moffitt's (1994) Figure 4. The black bars correspond to $1970-78$, the white bars to $1979-87$.

Gottschalk and Moffitt (1994) have provided indirect evidence for the kind of change in the environment that drives our interpretation. For the two periods 1970-78 and 197987, they summarized U.S. earnings distributions in ways that led them to conclude that both the 'permanent' and 'transitory' components of the distributions had spread out from one subperiod to the next. In particular, using data from the Michigan Panel Study on Income Dynamics (PSID), Gottschalk and Moffitt estimated for each subperiod the following decomposition of earnings $y_{i t}$ for individual $i$ in year $t: y_{i t}=\mu_{i}+\nu_{i t}$, where $\mu_{i}$ is an individual specific mean, or 'permanent' component of earnings, and $\nu_{i t}$ is a serially correlated 'transitory' component of individual $i$ 's earnings. They compared the distributions of the $\mu_{i}$ 's and the $\nu_{i t}$ 's for the two subperiods, and found the dispersion of both components to have increased. They and their discussants (see Katz (1994) and Dickens (1994)) interpreted these statistics in terms of how the increase in the dispersion of earnings observed during the 1980's in the U.S. was accompanied by an increase in the intertemporal volatility of an individual's earnings. Figures $2 \mathrm{a}$ and $2 \mathrm{~b}$ reproduce Gottschalk and Moffitt's figures 2 and 4, respectively, which depict the increased dispersion of both the $\mu_{i}$ distribution (figure $2 \mathrm{a}$ ) and the unconditional $\nu_{i t}$ distribution (figure $2 \mathrm{~b}$ ). ${ }^{4}$

\footnotetext{
4 For each subperiod, Figure $2 \mathrm{~b}$ summarizes the distributions (across $i$ ) of standard deviations
} 
The Gottschalk-Moffitt findings would be expected if the economic environment had become more turbulent between the earlier and later subperiods. Likewise, many informal accounts assert that the economic environment has become more turbulent in the last couple of decades. The oil price shocks of the 1970's and reallocations from manufacturing to services have each put economic turbulence into the industrialized world. In addition, the spread of new information technologies, declines in government regulation, competition from newly industrialized countries, and increasing internationalization of the production, distribution, and marketing of goods and services are rapidly changing the economic environment. Harris (1993) argues that 'globalization' has sped up in the last two decades and perhaps in the last decade in particular. We use Gottschalk and Moffitt's data description partly to inspire and partly to cross-check our model. Below, we show how increasing a key 'turbulence' parameter in our model serves to push the earnings distribution in ways depicted by Gottschalk and Moffitt.

Our thesis is that changed economic conditions from the mid-1970's onward can explain the high (long-term) unemployment in the welfare states. We formulate a general equilibrium search model where workers' skills depreciate during unemployment spells, and unemployment benefits are determined by workers' past earnings. Simulations of the model bring out the sensitivity of the equilibrium unemployment rate to the amounts of skills lost at lay offs. The analysis attributes the welfare states' persistently higher unemployment from the 1980 's to increased turbulence in the economic environment, while also explaining how lower unemployment rates in the 1950 's, the 1960 's and the early 1970 's were sustainable under more tranquil economic conditions. ${ }^{5}$

Relative to our 'tranquil times' setting, the 1980's (turbulent times) parameterization of our model exposes workers to the type of situation detected by Jacobson, LaLonde, and Sullivan (1993), who found that long-tenured displaced workers experienced large and

of $\nu_{i t}$ across time.

5 Our analysis agrees with the basic conclusion in a recent OECD study and policy report $(1994 a, b)$ that "it is an inability of OECD economies and societies to adapt rapidly and innovatively to a world of rapid structural change that is the principal cause of high and persistent unemployment". But we believe that a greater emphasis should have been put on reforming benefit systems, instead of putting it last among policy recommendations. 
enduring earnings losses. In their Pennsylvania sample from the 1980 's, a displaced worker experienced the following typical pattern: a sharp drop in earnings in the quarter a job was left, followed by a rapid recovery during next couple of years toward an eventual level of about $25 \%$ less than earned at the pre-displacement job. Figure 3 reproduces Jacobson, LaLonde, and Sullivan's Figure 1 which dramatically displays the pattern by showing the disparate expected earnings patterns of long-tenured workers who were displaced in the first quarter of 1982 compared to workers who remained employed throughout the period. In our model, a single parameter governs an exposure to the kinds of losses measured by Jacobson, LaLonde, and Sullivan. This parameter sets the immediate loss in human capital that a job loss imposes. Our parameterization of human capital dynamics, and of 'turbulence' in particular, also makes contact with Derek Neal's (1995) perspective on displaced workers. We model human capital as a state variable adhering partly to the worker and partly to a job. Neal shows how subsequent earnings of displaced workers depend on how closely allied a worker's new industry is to his old one, and interprets this finding as indicating a component of human capital surviving beyond the old match. ${ }^{6}$ Our parameterization of turbulence via human capital dynamics can be viewed as a short hand way of setting the mix of subsequent lines of work likely to confront an unemployed worker.

\footnotetext{
6 See Topel (1990) and the references in Neal (1995) for further evidence about the fates of displaced workers. Topel finds substantial evidence for job-specific human capital in the form of high returns to job tenure. In his conclusions, he opens the possibility that measured returns to job seniority are actually returns to industry or sector specific forms of human capital.
} 


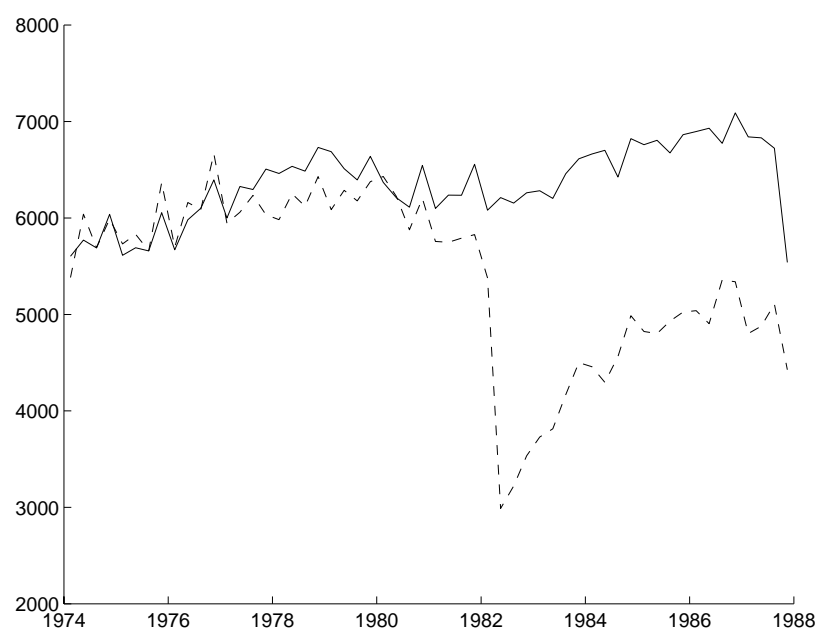

Figure 3. Quarterly earnings of high-attachment workers separating in the first quarter of 1982 and workers staying through 1986 . The solid line refers to stayers, the dashed line separators. Reproduction of Jacobson, LaLonde and Sullivan's (1993) Figure 1.

The unlucky workers in Jacobson, LaLonde, and Sullivan's study suffered substantial capital losses, but by returning to work, they partly recovered their lost earnings. What would similarly unlucky workers have done if they had been exposed to European levels of unemployment compensation? Our model suggests that such long-tenured displaced workers in Europe are likely to end up among the numerous long-term unemployed in the prime-age and older worker category. (Table 2 depicts the distribution of long-term unemployment across age categories.) The OECD has computed the welfare benefits available to the average 40-year-old worker with a long period of previous employment. Depending on family status, Table 3 shows net unemployment benefit replacement rates after tax and housing benefits. ${ }^{7}$ These generous benefits should be compared to the substantial income losses of displaced workers in Jacobson, LaLonde and Sullivan's study.

7 There are also other welfare programs in Europe, such as early retirement and disability insurance, which remove the assisted individuals from the labor force and the unemployment statistics. For example, totally disabled persons in the Netherlands in the 1980's were entitled to $70 \%$ (80\% prior to 1984 ) of last earned gross wage until the age of 65 -after which they moved into the state pension system. At the end of 1990 , disability benefits were paid to $14 \%$ of the Dutch labor force and $80 \%$ of them were reported to be totally disabled. (See OECD, 1992b.) 
Table 2: Distribution of long-term unemployment (one year and over) by age group in 1990

\section{Distribution of long-term unemployment}

(per cent of total long-term unemployment)

$\begin{array}{ccc}15-24 & 25-44 & 45+ \\ \text { years } & \text { years } & \text { years }\end{array}$

Belgium

17

62

20

France $^{a}$

13

63

23

Germany

8

43

48

Netherlands

13

64

23

Spain ${ }^{a}$

34

38

28

Sweden

9

24

67

United Kingdom

18

43

39

United States $^{a}$

14

53

33

a) Data for France, Spain and the United States refer to 1991.

Source: OECD, Employment Outlook (1993), Table 3.3. 
Table 3: Net unemployment benefit replacement rates $^{a}$ in 1994 for single-earner households by duration categories and family circumstances

\begin{tabular}{|c|c|c|c|c|c|c|}
\hline & \multicolumn{3}{|c|}{ Single } & \multicolumn{3}{|c|}{ With dependent spouse } \\
\hline & First & Second & Fourth & First & Second & Fourth \\
\hline & year & $\&$ third & $\&$ fifth & year & $\&$ third & $\&$ fifth \\
\hline & & year & year & & year & year \\
\hline Belgium & 79 & 55 & 55 & 70 & 64 & 64 \\
\hline France & 79 & 63 & 61 & 80 & 62 & 60 \\
\hline Germany & 66 & 63 & 63 & 74 & 72 & 72 \\
\hline Netherlands & 79 & 78 & 73 & 90 & 88 & 85 \\
\hline Spain & 69 & 54 & 32 & 70 & 55 & 39 \\
\hline Sweden $^{b}$ & 81 & 76 & 75 & 81 & 100 & 101 \\
\hline United Kingdom $^{b}$ & 64 & 64 & 64 & 75 & 74 & 74 \\
\hline United States & 34 & 9 & 9 & 38 & 14 & 14 \\
\hline $\begin{array}{l}\text { a) Benefit } \mathrm{e} \\
\text { percentag }\end{array}$ & $\begin{array}{l}\text { lemen } \\
\text { f net-o }\end{array}$ & $\begin{array}{l}\text { a net-of-t } \\
\text { earnings. }\end{array}$ & and hor & gg bene & asis as a & \\
\hline b) Data for & eden & he United & ingdom & er to & & \\
\hline
\end{tabular}

The next section extends our earlier model (Ljungqvist and Sargent, 1995a) by introducing a stochastic technology for skill accumulation and depreciation. Section 3 describes the calibration of the model. We compare the steady state for the welfare state to the laissez-faire outcome in Section 4. The two economies exhibit similar performance under tranquil economic conditions, when the loss of efficiency associated with the welfare state seems minimal. However, compared to the laissez-faire economy, the welfare state is much more vulnerable to economic shocks and turbulence. Section 5 traces out the 
impulse-response from an unexpected transient unemployment shock. The transient shock results in a prolonged period of long-term unemployment in the welfare state, whereas the recovery is almost immediate in the laissez-faire economy. ${ }^{8}$ Section 6 demonstrates how persistent economic turbulence leads to higher steady state unemployment in the welfare state than in the laissez-faire economy. In Section 7, we generate artificial earnings data from our model and compare them with the empirical patterns discerned by Gottschalk and Moffitt (1994), and Jacobson, LaLonde and Sullivan (1993). The final section contains concluding comments.

\section{The Economy}

There is a continuum of workers with geometrically distributed life spans, indexed on the unit interval with births equaling deaths. An unemployed worker in period $t$ chooses a search intensity $s_{t} \geq 0$ at a disutility $c\left(s_{t}\right)$ increasing in $s_{t}$. Search may or may not generate a wage offer in the next period. With probability $\pi\left(s_{t}\right)$, the unemployed worker receives one wage offer from the distribution $F(w)=\operatorname{Prob}\left(w_{t+1} \leq w\right)$. With probability $\left(1-\pi\left(s_{t}\right)\right)$, the worker receives no offer in period $t+1$. We assume $\pi\left(s_{t}\right) \in[0,1]$, and that it is increasing in $s_{t}$. Accepting a wage offer $w_{t+1}$ means that the worker earns that wage (per unit of skill) for each period he is alive, not laid off, and has not quit his job. The probability of being laid off at the beginning of a period is $\lambda \in(0,1)$. In addition, all workers are subjected to a probability of $\alpha \in(0,1)$ of dying between periods.

Employed and unemployed workers experience stochastic accumulation or deterioration of skills. There is a finite number of skill levels with transition probabilities from skill level $h$ to $h^{\prime}$ denoted by $\mu_{u}\left(h, h^{\prime}\right)$ and $\mu_{e}\left(h, h^{\prime}\right)$ for an unemployed and an employed worker, respectively. That is, an unemployed worker with skill level $h$ faces a probability $\mu_{u}\left(h, h^{\prime}\right)$ that his skill level at the beginning of next period is $h^{\prime}$, contingent on not dying. Similarly, $\mu_{e}\left(h, h^{\prime}\right)$ is the probability that an employed worker with skill level $h$ sees his skill level

8 Pissarides (1992) analyzes loss of skills during unemployment in a matching model, where it is also true that a transient shock to unemployment can have persistent effects. Firms are shown to create fewer jobs after the shock, since they are matching with workers of a lower average quality. Thus, this is another model of unemployment that is driven by the demand side for labor, while our paper focuses on the supply of labor in a welfare state. 
change to $h^{\prime}$ at the beginning of next period, contingent on not dying and not being laid off. In the event of a lay off, the transition probability is given by $\mu_{l}\left(h, h^{\prime}\right)$. After this initial period of a lay off, the stochastic skill level of the unemployed worker is again governed by the transition probability $\mu_{u}\left(h, h^{\prime}\right)$. All newborn workers begin with the lowest skill level.

A worker observes his new skill level at the beginning of a period before deciding to accept a new wage offer, choose a search intensity, or quit a job. The objective of each worker is to maximize the expected value $E_{t} \sum_{i=0}^{\infty} \beta^{i}(1-\alpha)^{i} y_{t+i}$, where $E_{t}$ is the expectation operator conditioned on information at time $t, \beta$ is the subjective discount factor, and $1-\alpha$ is the probability of surviving between two consecutive periods; $y_{t+i}$ is the worker's after-tax income from employment and unemployment compensation at time $t+i$ net of disutility of searching and working. ${ }^{9}$

Workers who were laid off are entitled to unemployment compensation benefits that are a function of their last earnings. Let $b(I)$ be the unemployment compensation to an unemployed worker whose last earnings were $I$. Unemployment compensation is terminated if the worker turns down a job offer with earnings that are deemed to be 'suitable' by the government in view of the worker's past earnings. Let $I_{g}(I)$ be the government determined 'suitable earnings' of an unemployed worker whose last earnings were $I$. Newborn workers and workers who have quit their previous job are not entitled to unemployment compensation. Both income from employment and unemployment compensation are subject to a flat income tax of $\tau$. The government policy functions $b(I)$ and $I_{g}(I)$ and the tax parameter $\tau$ must be set so that income taxes cover the expenditures on unemployment compensation in an equilibrium.

Let $V(w, h)$ be the value of the optimization problem for an employed worker with wage $w$ and skill level $h$ at the beginning of a period. The value associated with being unemployed and eligible for unemployment compensation benefits is given by $V_{b}(I, h)$, which is both a function of the unemployed worker's past earnings $I$ and his current skill level $h$. In the case of an unemployed worker who is not entitled to unemployment compensation,

9 Our analysis focuses on how the welfare state affects labor market incentives and efficiency in skill accumulation. We have abstracted from the benefits of risk sharing that government policies can provide when capital markets are incomplete. Adding such considerations would modify our results, but the forces at work in our analysis would remain. 
the corresponding value is denoted by $V_{o}(h)$ and depends only on the worker's current skill level. The Bellman equations can then be written as follows.

$$
\begin{aligned}
& V(w, h)=\max _{\text {accept }, \text { reject }}\left\{(1-\tau) w h+(1-\alpha) \beta\left[(1-\lambda) \sum_{h^{\prime}} \mu_{e}\left(h, h^{\prime}\right) V\left(w, h^{\prime}\right)\right.\right. \\
& \left.\left.+\lambda \sum_{h^{\prime}} \mu_{l}\left(h, h^{\prime}\right) V_{b}\left(w h, h^{\prime}\right)\right], V_{o}(h)\right\}, \\
& V_{b}(I, h)=\max _{s}\left\{-c(s)+(1-\tau) b(I)+(1-\alpha) \beta \sum_{h^{\prime}} \mu_{u}\left(h, h^{\prime}\right)\right. \\
& {\left[(1-\pi(s)) V_{b}\left(I, h^{\prime}\right)+\pi(s)\left(\int_{w \geq I_{g}(I) / h^{\prime}} V\left(w, h^{\prime}\right) d F(w)\right.\right.} \\
& +\int_{w<I_{g}(I) / h^{\prime}} \max _{\text {accept,reject }}\left\{(1-\tau) w h^{\prime}\right. \\
& +(1-\alpha) \beta\left[(1-\lambda) \sum_{h^{\prime \prime}} \mu_{e}\left(h^{\prime}, h^{\prime \prime}\right) V\left(w, h^{\prime \prime}\right)\right. \\
& \left.\left.\left.\left.\left.+\lambda \sum_{h^{\prime \prime}} \mu_{l}\left(h^{\prime}, h^{\prime \prime}\right) V_{b}\left(w h^{\prime}, h^{\prime \prime}\right)\right], V_{b}\left(I, h^{\prime}\right)\right\} d F(w)\right)\right]\right\} \\
& V_{o}(h)=\max _{s}\left\{-c(s)+(1-\alpha) \beta \sum_{h^{\prime}} \mu_{u}\left(h, h^{\prime}\right)\left[(1-\pi(s)) V_{o}\left(h^{\prime}\right)\right.\right. \\
& \left.\left.+\pi(s) \int V\left(w, h^{\prime}\right) d F(w)\right]\right\}
\end{aligned}
$$

Associated with the solution of equations (1)-(3) are two functions, $\bar{s}_{b}(I, h)$ and $\bar{w}_{b}(I, h)$, giving an optimal search intensity and a reservation wage of an unemployed worker with last earnings $I$ and current skill level $h$, who is eligible for unemployment compensation benefits; and two functions, $\bar{s}_{o}(h)$ and $\bar{w}_{o}(h)$, giving an optimal search intensity and a reservation wage of an unemployed worker with skill level $h$, who is not entitled to unemployment compensation. The reservation wage of an employed worker will be the same as for an unemployed worker without benefits, $\bar{w}_{o}(h)$, since anyone who quits his job is not eligible for unemployment compensation. 
We will study stationary equilibria, or steady states, for our economy. A steady state is defined in a standard way, as a set of government policy parameters, optimal policies $\left(\bar{s}_{o}(h), \bar{w}_{o}(h), \bar{s}_{b}(I, h), \bar{w}_{b}(I, h)\right)$ and associated time invariant employment and unemployment distributions and total unemployment compensation payments that satisfy workers' optimality conditions and the government's budget constraint. We compute a steady state as a fixed point in the tax rate $\tau$. For a fixed tax rate $\tau$, we solve workers' optimization problem and use the implied search intensities and reservation wages to deduce stationary employment and unemployment distributions, and unemployment compensation. A balanced government budget defines a fixed point in $\tau$, which is associated with a stationary equilibrium. ${ }^{10}$ After having found a stationary equilibrium, we compute various quantities such as GNP per capita, average productivity of employed workers, average skill level, average duration of unemployment, and measures of long-term unemployment.

\section{Calibration}

We set the model period to be two weeks. We set the discount factor $\beta=0.9985$, making the annual interest rate 4.0 percent. The probabilities of dying and being laid off are $\alpha=0.0009$, and $\lambda=0.009$, respectively. The working life of an individual is then geometrically distributed with an expected duration of 42.7 years. Similarly, the average time before being laid off (given that the worker has not quit or died) is 4.3 years. ${ }^{11}$

There are 21 different skill levels evenly partitioning the interval [1,2]. All newborn workers start out with the lowest skill level equal to one. After each period of employment that is not followed by a lay off, with a probability of 0.1 the worker's skills increase by one level (0.05 units of skills), and with probability .9 they remain unchanged. Employed workers who have reached the highest skill level retain those skills until becoming unemployed. As a point of reference, someone who starts out working with the lowest skill level

10 The iterative procedure picks the lowest possible $\tau$ consistent with a stationary equilibrium. We choose to focus on this the least distortionary tax rate and ignore any higher tax rates that might be consistent with other steady states. For example, there will always exist another stationary equilibrium with a $100 \%$ tax rate where all economic activities are closed down.

11 The parameterization of the probability of being laid off is motivated by Hall's (1982) observation that the average worker will hold 10 jobs in an entire career. 
will on average reach the highest skill level after seven years and eight months, conditional upon no job loss. The stochastic depreciation of skills during unemployment is twice as fast as the accumulation of skills. That is, after each period of unemployment, there is a probability of 0.2 that the worker's skills decrease by one level; otherwise they remain unchanged. The lowest skill level reached through depreciation is also an absorbing state until the unemployed worker gains employment. Upon being laid off in a period, the worker retains his skill level from the latest period of employment.

The disutility from searching and the function mapping search intensities into probabilities of obtaining a wage offer are assumed to be

$$
\begin{aligned}
& c(s)=0.5 s, \\
& \pi(s)=s^{0.3}, \quad \text { where } s \in[0,1] .
\end{aligned}
$$

The exogenous wage offer distribution is assumed to be a normal distribution with a mean of 0.5 and a variance of 0.1 that has been truncated to the unit interval (and then normalized to integrate to one). Since a worker's earnings are the product of his wage and his current skill level, it follows that observed earnings fall in the interval [0,2].

For purposes of awarding unemployment compensation, the government divides the earnings interval $[0,2]$ evenly into 15 earnings classes; let the upper limits of these classes be denoted $W_{i}$, for $i=1,2, \ldots, 15$. A laid off worker with last earnings belonging to earnings class $i$ receives an unemployment compensation of $0.7 \cdot W_{i}$ in each period of unemployment. However, the benefit is terminated if the worker does not accept a job offer associated with earnings greater than or equal to $0.7 \cdot W_{i}$. That is, a laid off worker faces both a 'replacement ratio' and 'suitable earnings' criterion equal to $70 \%$ of the upper limit of the earnings class containing his own last earnings before being laid off. New workers and quitters are not entitled to unemployment compensation.

The following numerical simulations will make it clear that there are two key parameters driving our analysis; the fact that unemployment compensation is a function of past earnings ( $70 \%$ replacement ratio), and the amount of immediate loss in human capital that a job loss imposes (zero in this initial parameterization of 'tranquil times'). Perturbations in the latter parameter will be used to capture the notion of 'economic turbulence'. Our 
qualitative findings are fairly robust to changes in other parameters. For example, similar results were obtained in earlier simulations where we had doubled both the range of skills and the transition probabilities of gaining a skill level when remaining employed for two periods and of losing a skill level when being unemployed for two consecutive periods.

\section{Economic Forces at Work}

Given the calibration above, the tax rate that balances the government budget is $\tau=$ 0.0285. To shed light on the workings of this welfare state (WS), we will now contrast its steady state to that of a laissez-faire economy (LF), in which there is no government intervention whatsoever.

Table 4: Steady state values for the WS economy and the LF economy.

$\begin{array}{lll} & \text { WS } & \text { LF } \\ \text { GNP per capita }{ }^{\dagger} & 1.542 & 1.555 \\ \text { Average productivity of employed }^{\dagger} & 1.657 & 1.659 \\ \text { Average wage of employed } & 0.879 & 0.878 \\ \text { Average skill level in the population } & 1.876 & 1.880 \\ \text { Unemployment rate } & 6.95 \% & 6.28 \% \\ \text { Average duration of unemployment } & 13.3 \text { weeks } & 11.8 \text { weeks } \\ \text { Percentage of unemployed at a point in } & & 9.8 \% \\ \text { time with spells so far } \geq 6 \text { months } & 12.6 \% & 0.7 \% \\ \text { Percentage of unemployed at a point in } & & \\ \text { time with spells so far } \geq 12 \text { months } & 1.3 \% & 580.2 \\ \text { Discounted expected net consumption } & & \\ \text { of a newborn worker } & \end{array}$

Table 4 shows that the two economies have very similar steady states. Both their pro- 
duction and average skill levels are indistinguishable, and the unemployment rate is less than seven tenths of a percentage point higher in the WS economy. As a welfare measure, the discounted expected net consumption stream of a newborn worker differs by only four weeks of per capita GNP (two 2-week periods). We conclude that the efficiency costs associated with the welfare system are relatively small. However, behind these numbers lurk important differences in unemployment dynamics. It is true that the average unemployment spell is very similar across the two economies: 13.3 weeks in the WS economy as compared to 11.8 weeks in the LF economy. But the WS economy has more dispersion in the duration of unemployment spells, as indicated by the fractions of long-term unemployed at any point in time. The percentage of currently unemployed workers with spells to date greater than or equal to 6 months (12 months) is $12.6 \%$ (1.3\%) in the WS economy as compared to $9.8 \%(0.7 \%)$ in the LF economy.

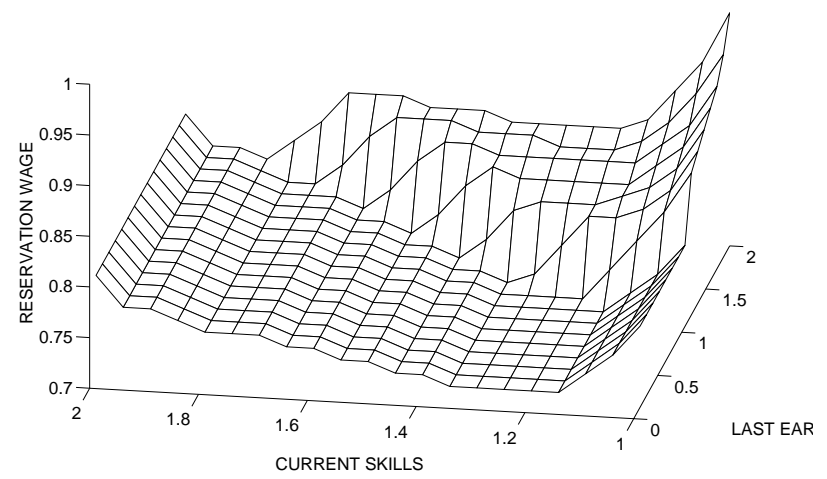

Figure 4. Reservation wages in the WS economy of unemployed workers with unemployment compensation. The reservation wages are drawn as a function of the unemployed workers' current skills and their last earnings before being laid off.

We compare the WS economy and the LF economy by first looking at unemployed workers' behavior in terms of reservation wages and search intensities. The reservation wages in the WS economy of unemployed workers receiving unemployment benefits are depicted in Figure 4. The reservation wages are graphed as a function of the unemployed 
workers' current skills and their last earnings before being laid off. Not surprisingly, the reservation wage is a positive function of last earnings, which determine the level of unemployment compensation. For example, the reservation wage of someone with the lowest skill level of one, but with the highest possible last earnings, is 0.93 . This corresponds to a worker who once had attained a high skill level while making a wage at the top of the wage distribution. If such a worker with a high unemployment benefit happens to lose all his skills due to a prolonged period of unemployment, he will be extremely picky in terms of the wage offers he will accept. That is, before giving up his generous benefits, he wants to find a very good wage offer to compensate for his skill loss. Since such high wage offers are hard to find, this worker will also be unwilling to expend too much energy in searching for a new job. As can be seen in Figure 5, the optimal search intensity of such a worker is a mere 0.06 . Figure 5 shows also how the search intensity is lower for unemployed workers with both high benefits and high current skills that have not yet deteriorated due to unemployment. The $70 \%$ replacement ratio causes these workers to consume some "leisure" by reducing their search intensity.

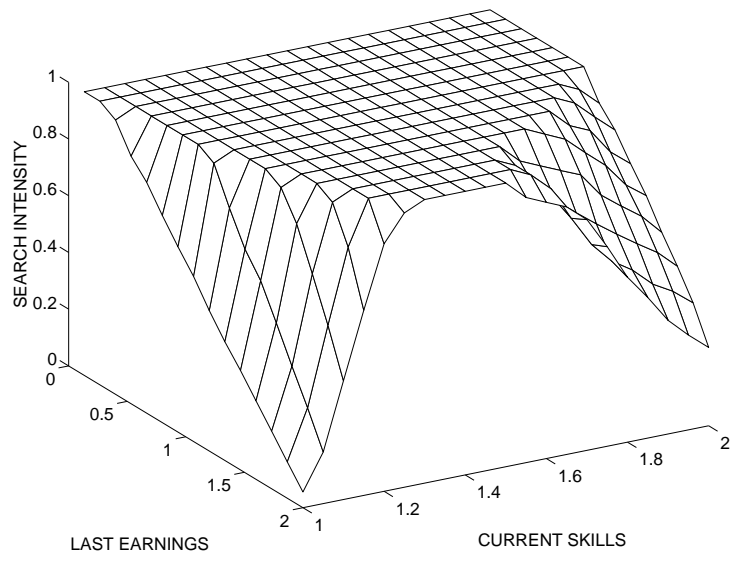

Figure 5. Search intensities in the WS economy of unemployed workers with unemployment compensation. The search intensities are drawn as a function of the unemployed's current skills and their last earnings before being laid off. 


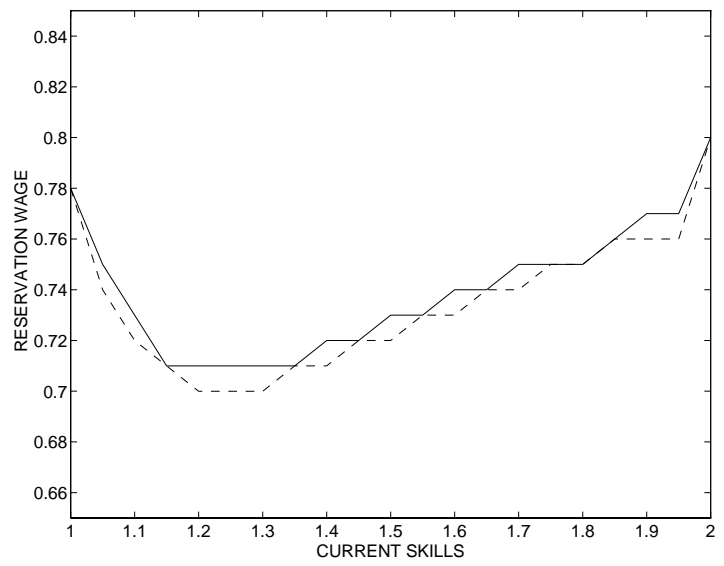

Figure 6. Reservation wages of unemployed workers without benefits drawn as a function of their current skills. The solid line describes the WS economy and the dashed line refers to the LF economy.

Unemployed workers without benefits in the WS economy and the unemployed in the LF economy prefer to choose the maximum search intensity of one. Their reservation wages can be found in Figure 6. Contrasting Figure 6 to Figure 4 for the WS economy, the reservation wage of an unemployed worker without benefits is always less than or equal to the reservation wage of an unemployed worker with benefits, for any given skill level. Unemployment spells are of course more costly to the unemployed without unemployment compensation. Across the WS and the LF economies, there is a slight tendency for higher reservation wages in the WS economy. An unemployed worker without benefits in the WS economy takes into account the future potential benefits from the unemployment compensation program. It is important for the worker to become vested at a high wage rate in the event of being laid off. The U-shaped pattern for reservations wages in Figure 6 emerges from the depreciation and accumulation of skills. On the one hand, at the lower end of the skill spectrum, unemployed workers have less to lose in terms of skills from an extended period of unemployment. They therefore tend to choose higher reservation wages as compared to unemployed workers with skills in the intermediate range. On the other hand, at the upper end of the skill spectrum, the potential for further skill accumulation becomes smaller and the emphasis shifts towards the search for higher wages, i.e., the reservation wage curve starts to slope upward. 
The effects of different search behavior in the LF economy and the WS economy are illustrated in Figure 7. The figure follows a cohort of workers who lost their jobs after having reached the highest skill level. At different lengths of the unemployment spell, the curves show the fraction of still unemployed workers who gain employment in the current 2-week period ('hazard rate'). The dashed curve pertains to the LF economy without any unemployment compensation benefits. Since all unemployed workers in the LF economy choose the highest search intensity, the shape of the curve is solely determined by how reservation wages vary with skill levels. Recall from Figure 6 that reservation wages must initially be decreasing when skills start depreciating from the maximum level. That is, over time, unemployed workers become more and more concerned about additional losses of skills. Their willingness successively to reduce their reservation wages explains the rising hazard of gaining employment during the first couple of years of unemployment. After three years, the remaining unemployed have lost enough of their skills that further losses are less of a concern to them. Their increasing reservation wage policy in Figure 6 translates into a falling hazard of gaining employment in Figure 7. The hazard of gaining employment in any given 2-week period levels out at $15.8 \%$ in the LF economy. 


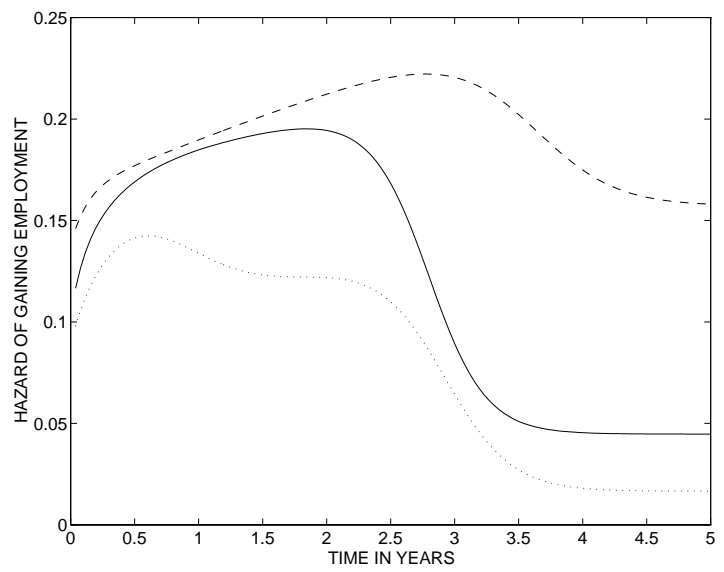

Figure 7. The hazard of gaining employment as a function of the length of the unemployment spell, given an initial skill level equal to the highest one. The curves show the fraction of still unemployed workers who gain employment in any given 2 -week period after the lay off. The dashed line pertains to the LF economy; the solid and dotted lines refer to the WS economy with the workers' last earnings belonging to the third highest earnings class and the highest earnings class, respectively.

The solid line in Figure 7 traces the corresponding hazard of gaining employment for a cohort of workers who become unemployed at the highest skill level in the WS economy with their last earnings in the third highest earnings class. This group of workers is the most numerous one in a steady state, comprising roughly $30 \%$ of all employed workers. Over the first two years, the hazard of gaining employment is quite similar to that in the LF economy, but thereafter diverges considerably. A long-term unemployed worker in the WS economy becomes disillusioned, and his prospect of finding a job seems less attractive over time as compared just to living on his unemployment compensation benefits. As a result, the worker is both raising his reservation wage and reducing his search intensity, as earlier shown in Figures 4 and 5. The hazard of gaining employment finally settles down to $4.5 \%$, which is much smaller than the $15.8 \%$ in the LF economy. The third dotted line in Figure 7 shows the hazard of gaining employment if the cohort of laid off workers had last earnings in the highest earnings class. With these even more generous unemployment benefits, the hazard function is naturally lower, and it converges to a low of $1.7 \%$. Fortunately, 
these potential incentive problems have only a small impact on the steady state of the WS economy, as earlier shown in Table 4. Loosely speaking, the incentive problems are minor thanks to the relatively low average duration of unemployment.

\section{A Transient Economic Shock}

The unemployment dynamics described in the previous section make the WS economy more vulnerable to economic shocks. This section demonstrates how a transient shock can cause a prolonged period of long-term unemployment in the WS economy while the LF economy is more resilient. Specifically, we will trace out both economies' responses to an unexpected transient unemployment shock. We assume that once and for all, the normal lay off rate of 0.009 rises 20 -fold to 0.18 in a single 2 -week period at time 0 in the following figures. Also, everyone who becomes unemployed in this particular period immediately loses all of his accumulated skills. After this one-period shock, both economies once again experience the normal lay off rate and rates of skill depreciation and accumulation. All policy parameters such as taxes and the unemployment compensation program are kept constant throughout the experiment, which means that the workers' decision rules stay the same over time, and that the economies will eventually return to their steady states. During the transition, additional government expenditures on unemployment compensation in the WS economy are assumed to be financed by levying lump-sum taxes.

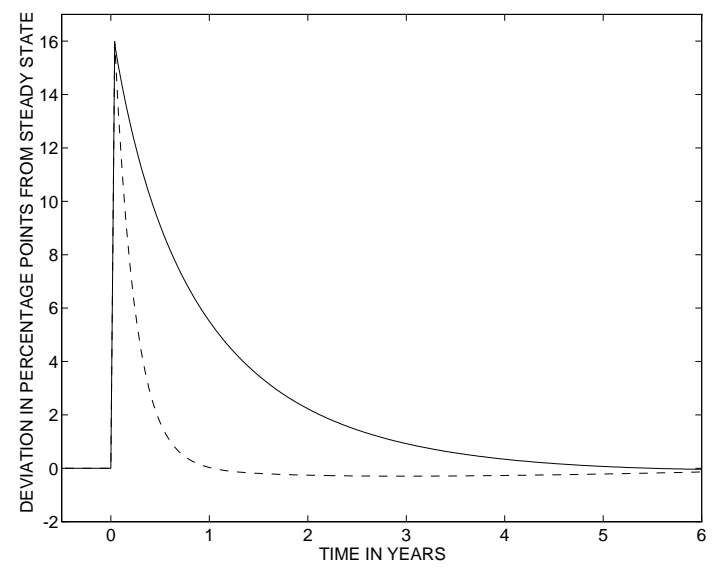

Figure 8. Response of unemployment. The solid line describes the WS economy and the dashed line refers to the LF economy. 
As can be seen in Figure 8, the unemployment rates in both economies jump up initially by roughly 16 percentage points. However, the unemployment rates take very different paths thereafter. In the LF economy, the high unemployment rate dies out quickly because the unemployed workers 'bite the bullet' and search intensively for less well-paying jobs as compared to their lost earnings. In contrast, the WS economy is plagued by a prolonged period of unemployment since the unemployed workers with their depreciated skills have difficulty finding jobs that they prefer to their unemployment compensation based on past earnings. Besides their higher reservation wages, these workers also reduce search intensities to balance the small prospective gains from search against the utility costs associated with search.

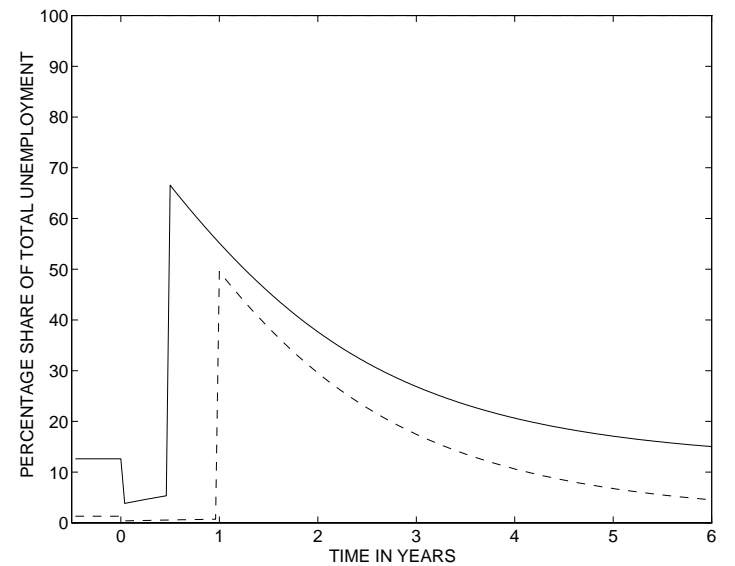

Figure 9.a. Response of the decomposition of the unemployed in the WS economy with respect to the length of their unemployment spells so far. The percentage of unemployed workers with at least 6 months (12 months) of unemployment to date is below the solid line (dashed line). The percentage above the solid line is then unemployed workers who have until now been unemployed for less than 6 months.

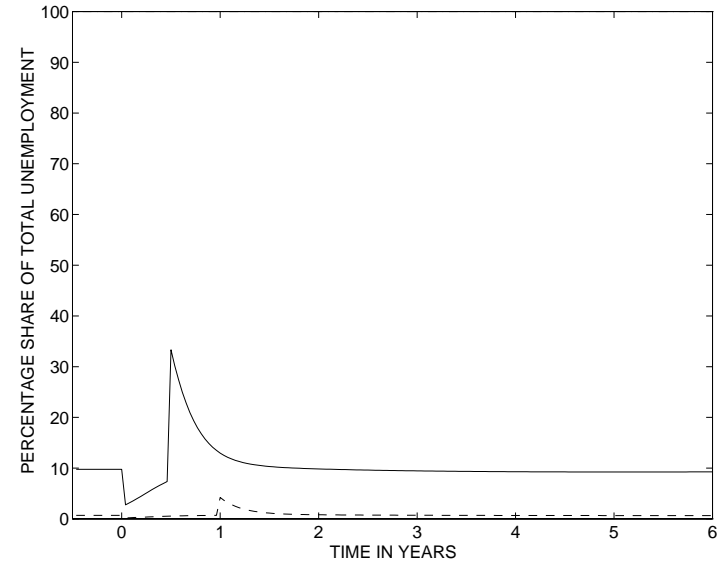

Figure 9.b. Response of the decomposition of the unemployed in the LF economy with respect to the length of their unemployment spells so far. The percentage of unemployed workers with at least 6 months (12 months) of unemployment to date is below the solid line (dashed line). The percentage above the solid line is then unemployed workers who have until now been unemployed for less than 6 months.

The drawn out unemployment response in the WS economy is naturally associated with longer unemployment spells. Figures 9.a and 9.b show how long-term unemployment gradually emerges after the shock. At any point in time, the figures decompose unemployment into the fraction of unemployed workers who have to date been unemployed for at 
least one year (below the dashed line), those who have so far suffered unemployment of less than a year but at least 6 months (between the solid line and the dashed line), and those who have until now been unemployed for less than 6 months (above the solid line). Not surprisingly, both of the first two measures of unemployment fall at the time of the shock, since there is a flood of newly laid off workers into unemployment. The two measures then rise predictably after 6 months and 12 months, respectively. The problem of long-term unemployment in the WS economy shows up starkly in Figure 9.a. At the peaks of the two long-term unemployment measures, there is first a fraction of $66.6 \%$ of all unemployed workers being unemployed for at least half a year, and later $49.5 \%$ of all unemployed have to date experienced unemployment for a year or more. In contrast, the corresponding numbers for the LF economy in Figure $9 . \mathrm{b}$ are $33.3 \%$ and $4.2 \%$, respectively. Besides the lower incidence of long-term unemployment, the LF economy shows hardly any persistence in the fractions of long-term unemployed as compared to the WS economy.

The exogenous jump in the lay off rate and the accompanying depreciation of workers' skills affect the economies' GNP adversely. Figure 10 shows a sharp drop of around $17 \%$ in GNP. The faster recovery in the LF economy as compared to the WS economy is due to the fact that its labor force is returning to work more quickly. A conceivably misleading measurement of the economies' performances is the change in average productivity of employed workers. At the end of the first year, Figure 11 shows that the average productivity in the WS economy falls by $4.7 \%$ while the decline in the LF economy is significantly larger at $7.2 \%$. The explanation for this difference is that laid off workers with depreciated skills return to employment much faster in the LF economy, while they are slowly phased in to the WS economy. The long-term unemployment in the WS economy is in this way concealing the severity of the exogenous shock to workers' skills. 


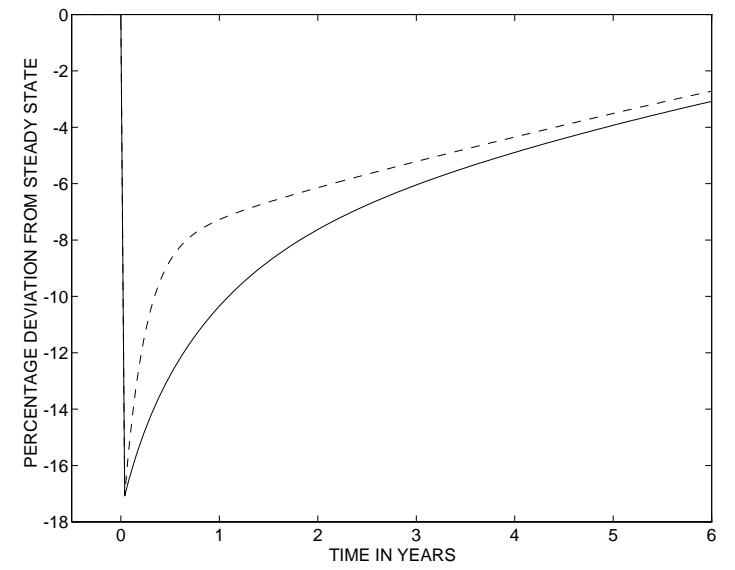

Figure 10. Response of GNP. The solid line describes the WS economy and the dashed line refers to the LF economy.

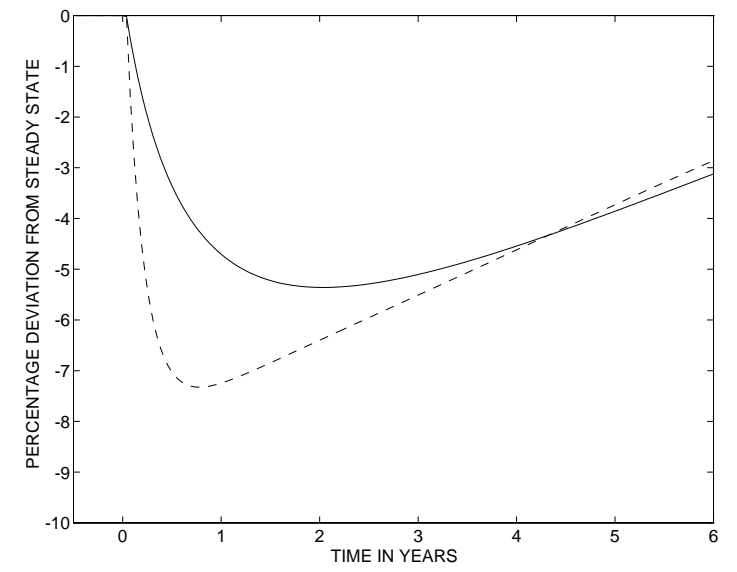

Figure 11. Response of average productivity of employed workers. The solid line describes the WS economy and the dashed line refers to the LF economy.

Finally, the budgetary impact of the shock on the WS government is displayed in Figure 12. The deficit financed with lump-sum taxation reaches a high of $12.5 \%$ as a share of steady state GNP, and is persistent due to the economy's unemployment problems.

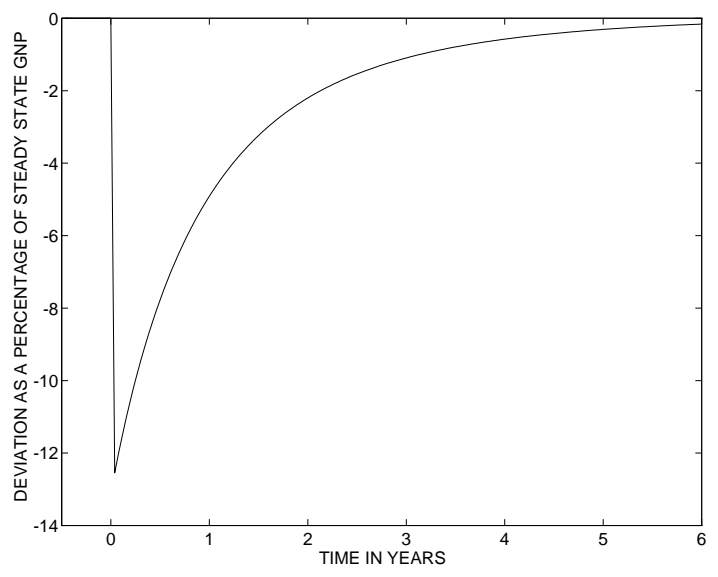

Figure 12. Response of government finances in the WS economy. 


\section{Persistent Economic Turbulence}

The previous section indicated that the welfare state is prone to experience enduring periods of long-term unemployment after transient economic shocks. This section demonstrates how persistent economic turbulence increases the unemployment rate in welfare states. Specifically, we compute and compare the steady states for different economic environments with more or less economic turbulence. Economic turbulence is defined in terms of the mean and variance of skill losses associated with lay offs. We now let the skills of a newly laid off worker be distributed according to the left half of a normal distribution with the range starting at the lowest possible skill level and ending at the worker's skill level before the lay off. During the unemployment spell itself and at times of continuing employment, skill depreciation and accumulation are governed by the same transition probabilities as before.

With this definition of economic turbulence, the earlier steady state serves as a benchmark case with zero variance. Recall that our earlier assumption was that a newly laid off worker kept his skill level from last period of employment. Let us now consider three alternative environments with different probability distributions for skills of newly laid off workers, as depicted in Figure 13. The graph is drawn for a worker who had attained the highest skill level of 2 before being laid off. The same distributions apply to a worker with another skill level so long as we rescale the range so that it ends at that particular worker's skill level before the lay off. The exact distributions in Figure 13 are obtained by taking the left side of a normal distribution that is confined to and centered on the unit interval. The solid, dotted, and dashed lines correspond to variances of .02, .03, and .04, respectively. The left halves of these distributions are then normalized to integrate to one. Finally, since there is a discrete number of skill levels in the model, the distributions in Figure 13 are transformed into step functions for each kind of laid off worker. 


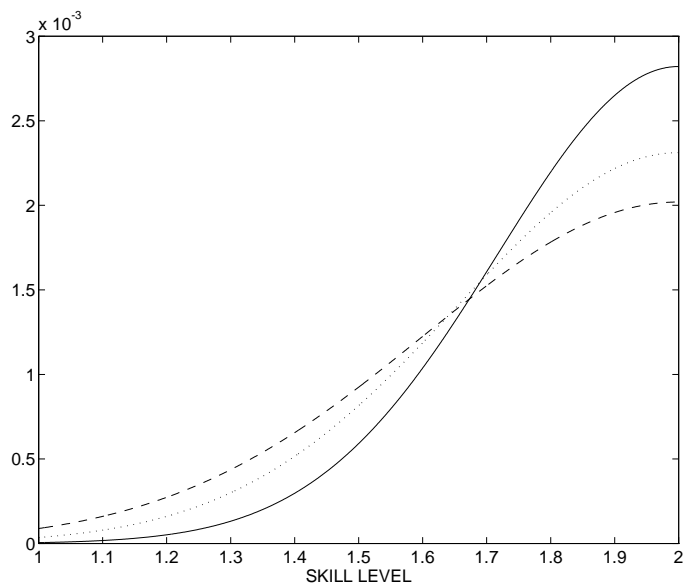

Figure 13. The probability distribution of a worker's skills immediately after a lay off. The range starts at the lowest skill level of 1 and ends at the worker's skill level before the lay off. The graph is drawn for a worker who had attained the highest skill level of 2 before the lay off. The solid line, dotted line, and dashed line refer to different degrees of economic turbulence indexed by variance $.02, .03$, and .04 , respectively.

Table 5 reports the steady states for the WS economy and the LF economy when assuming alternative degrees of economic turbulence. The unemployment response to increased economic turbulence is strikingly different in the two economies. The steady states in the LF economy are associated with a slightly lower unemployment rate when economic turbulence increases. The primary explanation for this is that the greater loss of skills among laid off workers, who have typically accumulated the highest level of skills before the lay off, causes more unemployed workers to end up in the middle skill range where reservation wages are the lowest as indicated in Figure 6 . In contrast, the unemployment rate in the WS economy rises sharply in response to increased economic turbulence. The explanation for this is two-fold. First, larger numbers of unemployed workers find themselves with considerable losses of skills while being entitled to generous unemployment compensation benefits. That is, the incentive problems identified earlier by Figure 7 now affect a larger group of unemployed. Second, the larger uncertainties associated with skill accumulation and increased taxes make it even less attractive for an unemployed worker to look for and 
accept a job, especially if he is currently receiving generous unemployment compensation. As a result, these unemployed workers choose to lower their search intensities and raise their reservation wages. This exacerbates the economy's unemployment problem.

Table 5 shows also that a higher WS unemployment rate in a more turbulent economic environment is accompanied by considerably longer average unemployment spells. In the most turbulent environment, the average duration of unemployment is 31.8 weeks as compared to the 13.3 weeks in the benchmark case without any turbulence. Moreover, the fractions of long-term unemployed explode in the WS economy. The percentage of currently unemployed workers with spells to date of six months or more rises from $12.6 \%$ in the WS economy without turbulence to $63.1 \%$ in the WS economy with most economic turbulence. Concerning the percentage of unemployed workers with spells to date of one year or more, the corresponding increase for the WS economy is from $1.3 \%$ to $55.6 \%$. In contrast, the small numbers of long-term unemployed in the LF economy stay virtually unchanged in response to increased economic turbulence.

Since economic turbulence is modeled in the form of risk of more skill losses at a moment of lay off, it follows that a higher degree of turbulence must be associated with welfare reductions. The LF economy in Table 5 posts a $8.0 \%$ reduction in the discounted expected net consumption of a newborn worker when moving from an environment with no turbulence to the highest degree of turbulence. The corresponding relative welfare loss in the WS economy is close to twice as large at $15.8 \%$, due to its malfunctioning labor market with excessive unemployment. Despite the dismal performance of the WS economy, the average productivity of employed is comparable to the LF economy for different degrees of turbulence. The good productivity record in the WS economy actually reflects the low job finding rate among long-term unemployed workers with depreciated skills.

Finally, when trying to solve for a WS steady state with a variance of .05 , a vicious circle develops on the computer. Exploding government expenditures on unemployment compensation chase an exploding unemployment rate without finding a feasible steady state with government budget balance. This breakdown of the computations mirrors a potential instability of a generous welfare state. The feasibility of the system depends critically upon the number of workers that has virtually withdrawn from active labor market 
Table 5: Steady state values for the WS economy and the LF economy with different degrees of economic turbulence.

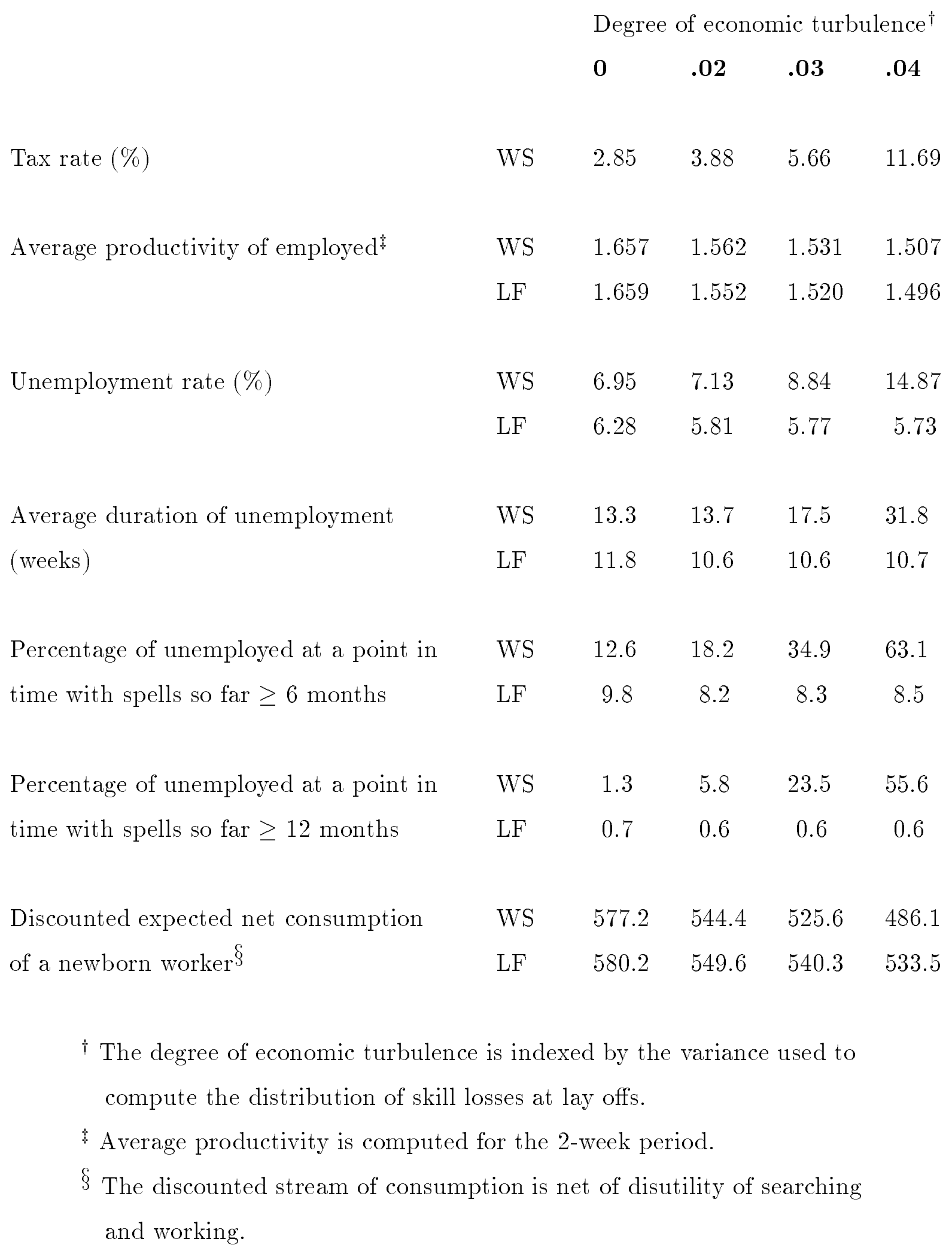


participation because of disincentives. The size of this group can increase dramatically in response to a more turbulent economic environment. As a consequence, a welfare regime that was earlier sustainable under more tranquil economic conditions can suddenly become infeasible, and lead to a mounting budget deficit.

\section{Artificial Earnings Data}

We can use our model as a laboratory for trying to replicate aspects of earnings dynamics described Gottschalk and Moffitt (1994) and Jacobson, LaLonde, and Sullivan (1993), described in section 1 . We first use a comparison of our model under 'tranquil' and 'turbulent' times to replicate Gottschalk and Moffitt's earnings decompositions across two subperiods.

An equilibrium of our model yields earning dynamics for a distribution of individuals. For given parameter values, an equilibrium of our model produces a stationary probability distribution over the individual state variables, namely, $(h, w, I)$ and an additional state variable recording whether an individual is employed or unemployed with or without unemployment compensation. We can draw a set of 'initial conditions' - really individuals from this distribution, then apply the individual equilibrium transition dynamics to construct a panel of individuals' earnings. We can then use artificial panels for two parameter settings, one with lower turbulence than the other, to prepare versions of Gottschalk and Moffitt's figures. This tells whether our way of modeling increased turbulence generates the observed altered earnings outcomes.

For the laissez-faire economy, we generated artificial panels of length nine years with 10,000 individuals for two different subperiods; relatively 'tranquil' economic times and more 'turbulent' times as indexed in Table 5 by variances .02 and .04 , respectively. The former panel is meant to represent the period 1970-78 in the Gottschalk-Moffitt study, while the latter panel would then correspond to the period 1979-87. For both panels, we use the equilibrium distribution of workers who have been in the labor force for 20 years as initial conditions. A period of 20 years should suffice to remove the initial life cycle pattern in the accumulation of human capital among newborn workers. (Recall that, in our calibration, it takes on average seven years and eight months to move from the lowest to the highest skill level for someone who is continuously employed.) 
Figures 14a and 14b summarize the Gottschalk-Moffitt decomposition for our two artificial panels, which should be compared with Figures $2 \mathrm{a}$ and $2 \mathrm{~b}$ above. Evidently, an increase in our turbulence parameter spreads the distributions of both components of the Gottschalk-Moffitt decomposition in the direction observed. However, there are a couple of differences in terms of the range of the distributions. The fact that our distribution of permanent earnings in Figure 14a spans a smaller range than the Gottschalk-Moffitt data is not surprising. Our artificial panel contains a group of very homogeneous individuals who are ex ante identical, while the PSID used by Gottschalk and Moffitt comprises a diverse group of American males with different educational backgrounds. It is also noteworthy that the increased earnings variability in the more turbulent period in our Figure 14b occurs at lower standard deviations as compared to Gottschalk and Moffitt's findings. In this respect, the increase in economic turbulence in our parameterization of the 1980's falls short of the changes documented for the U.S.

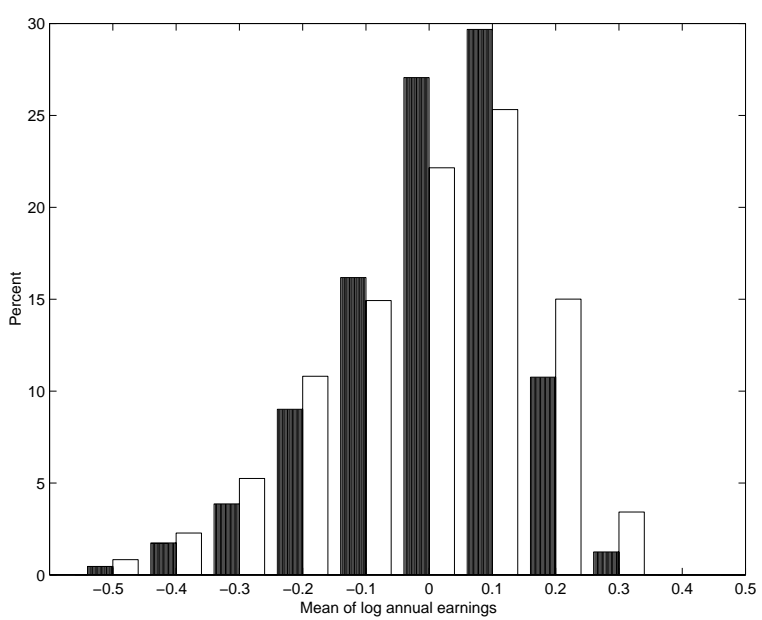

Figure 14a. Distribution of permanent earnings in the laissez-faire economy. The black bars and the white bars correspond to degrees of economic turbulence indexed by variance .02 and .04 , respectively.

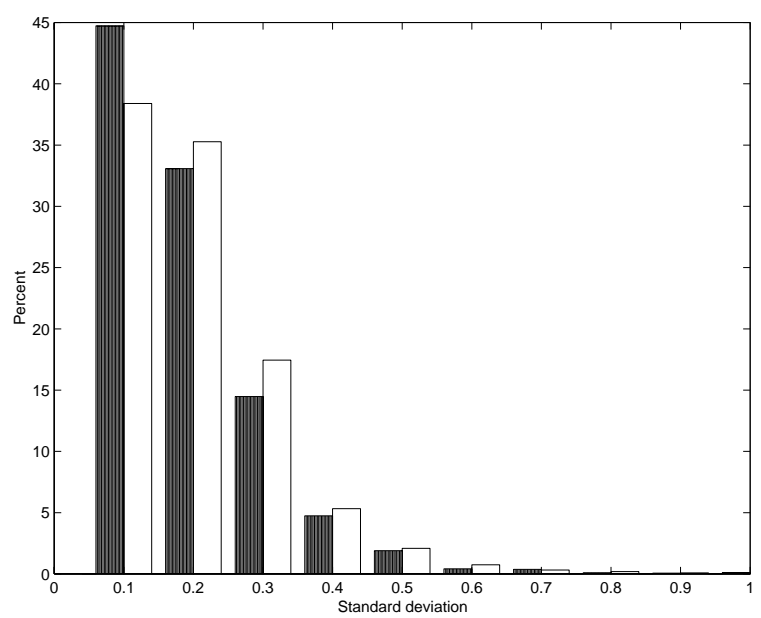

Figure 14b. Distribution of individuals' standard deviations of transitory earnings in the laissezfaire economy. The black bars and the white bars correspond to degrees of economic turbulence indexed by variance .02 and .04 , respectively.

We now turn to replicate a version of Jacobson, LaLonde and Sullivan's (1993) study of income losses experienced by long-tenured displaced workers in the 1980's. Once again, we construct an artificial panel to compare to Jacobson, LaLonde and Sullivan's empirical 
findings. We study the earnings losses that arise in our model of turbulent times as indexed by variance .04 in Table 5. Using the equilibrium distribution of workers who have been in the labor force for 20 years as initial conditions, we follow 100,000 workers in our model who survive for the next 11 years. Let us call this period '1976-86'. At the end of 1986, a total of 2889 workers have stayed with the same job over the whole period. This reference group is labeled the 'stayers', borrowing Jacobson, LaLonde and Sullivan's terminology, and their earnings are given by the solid line in Figure 15.

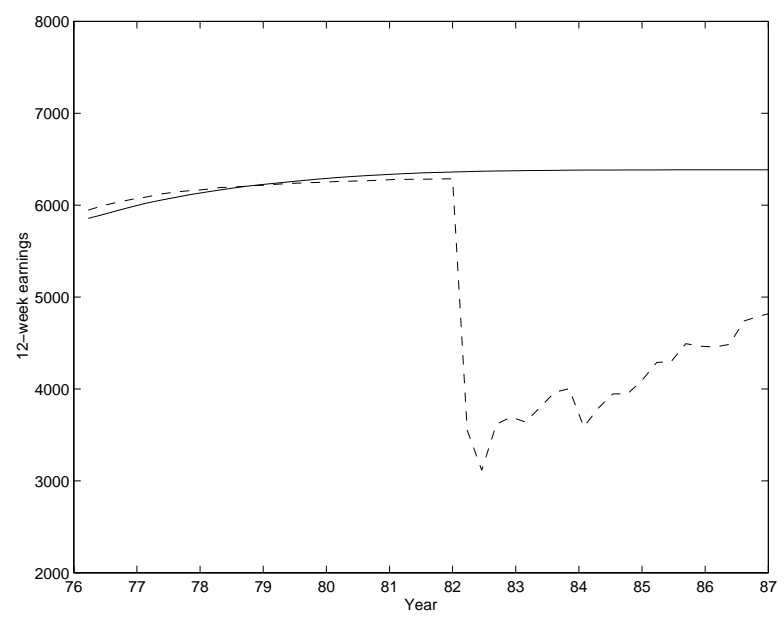

Figure 15. 12-week earnings of high-attachment workers separating in the first 12 -week period of 1982 with skill losses exceeding $40 \%$ and workers staying through 1986. The solid line refers to stayers, the dashed line separators. The simulation is based on the laissez-faire economy with economic turbulence indexed by variance .04 . (The earnings figures are multiplied by a factor of 600 to facilitate comparison with Figure 3.)

In the artificial panel, 629 workers retain the same job during the first six years of the period but get laid off in the first 12 weeks of 1982. At the time of the layoff, these 'separators' experience various amounts of instantaneous loss in human capital (when their new skill levels are drawn from the dashed distribution in Figure 13); skill losses exceeding $10 \%, 20 \%, 30 \%$ and $40 \%$ are experienced by $298,157,71$ and 19 workers, respectively. ${ }^{12}$ To

12 In our calibration, no one can lose more than $50 \%$ of his skills since the highest skill level is 2 while the lowest possible (endowed) skill level is 1 . 
reproduce the earnings dynamics in Figure 3 above from Jacobson, LaLonde and Sullivan's study (their Figure 1), we are led to draw the dashed line in Figure 15 representing the earnings of the worst losers, i.e., the displaced workers experiencing skill losses in excess of $40 \%$. The patterns in the data (Figure 3 ) and the artificial data (Figure 15) are the same.

To conclude, the artificial earnings data implied by our analysis are encouraging for our theoretical approach but discouraging for the viability of current welfare systems in Europe. The simulations suggest that the mechanism generating high long-term unemployment in our model operates at much lower levels of economic turbulence than those observed in the U.S. The analysis therefore raises grave concerns about the sustainability of the generous European unemployment compensation schemes in Table 3 with virtually indefinite duration.

\section{Concluding Discussion}

High unemployment rates in the European welfare states have been attributed to many causes such as insiders versus outsiders, adjustment costs in firing and hiring, lack of wage flexibility, shortage of physical capital, mismatch in labor markets, and insufficient demand. All these alternative theories focus on the demand side for labor while largely ignoring the supply side. Our paper takes the opposite approach and only explores the effects of the welfare state upon the supply of labor. As mentioned in the introduction, explanations based on workers' distorted incentives in the face of generous entitlement programs have been rare in this context, the main reason probably being that empirical work has had difficulties in establishing causal relationships between changes in welfare programs and the unemployment rate. Specifically, the persistent increase in European unemployment since the 1980's does not seem to have been preceded by any major welfare reform. Instead, the generosity of welfare programs has been increasing steadily over a long period of time without any discrete jump at the time when the unemployment rate rose.

Our analysis suggests that the smooth performance of the welfare states in the 1950's and 1960's concealed an inherent instability in these economies. In our model, a welfare state with a very generous entitlement program is a virtual 'time bomb' waiting to explode. So long as the economy is not subject to any major economic shocks, the welfare state can function well. Workers who get laid off with generous unemployment compensation can 
without too much trouble get back into employment at working conditions similar to their previous jobs. That is, the availability of 'good jobs' for unemployed workers counteracts the adverse effects of generous unemployment compensation. However, at the time of a large shock, generous unemployment compensation hinders the process of restructuring the economy. Laid off workers then lack the incentives quickly to accept the transition to new jobs where skills will once again have to be accumulated. Consequently, there can be a lengthy transition phase with long-term unemployment largely attributable to the existence of welfare programs. This causality is hard to detect from time series data because there need not have been any changes in the welfare programs at the time of the shock.

Our model of ex ante identical individuals who can only accumulate human capital through work experience is best thought of as a model of blue-collar workers. When joining the labor force, all workers in our model face the same probability of experiencing longterm unemployment during their working life. The workers who end up being unemployed for long terms are ones who have lost considerable amounts of skills at the time of their lay offs and/or during their unemployment spells. The fact that welfare benefits are based on past earnings causes these workers with depreciated skills literally to 'bail out' from the active labor force by choosing low search intensities and high reservation wages. In other words, our model predicts that workers who have accumulated significant amounts of skills and subsequently lose these skills are more prone to end up as long-term unemployed. This view is consistent with OECD"s (1992a, page 67) observation that "[f]ormer manufacturing workers tend to be over-represented among the long-term unemployed, reflecting the impact of structural adjustment in industry."

Our model bears some interesting connections to aspects of the literature on 'duration dependence' and 'heterogeneity' as determinants of the observed hazard of leaving unemployment. ${ }^{13}$ Our model combines elements of both. Our specification makes human

13 An example of a study finding 'duration dependence' in unemployment spells is Jackman and Layard (1991). However, it is fair to say that the general evidence for duration-dependence is mixed and controversial. See Heckman and Borjas (1981) for a treatment of the conceptual issues, and for an interpretation of a data set in terms of illusory duration dependence coming from heterogeneity and sample selection bias. 
capital reside partly in the worker, partly in the 'job' or 'industry'. Loss of the job-specific or industry-specific part (see Derek Neal (1995)) is captured by the instantaneous capital loss that a separation triggers. The remaining human capital dynamics are attached to the individual, when unemployed; they build in a 'duration dependence' for the probability of leaving unemployment. As indicated by our calculations with the model as calibrated for 'tranquil' times, the depreciation of skills during spells of unemployment (the source of duration dependence) is simply too slow to have much affect on the amount of long-term unemployment. The primary cause of long-term unemployment in our 'turbulent' times is the instantaneous loss of skills at layoffs. Our probabilistic specification of this instantaneous loss creates heterogeneity among laid off workers having the same lost earnings. Since unemployed people with the same past earnings receive identical unemployment compensation, our analysis shows that workers with larger losses of skills tend to choose relatively higher reservation wages (per unit of remaining skills) and lower search intensities. These explain their higher incidence of long-term unemployment.

Our analysis highlights the welfare state's vulnerability in times of economic turbulence. In the last two decades, the rapid restructuring from manufacturing to the service industry, the adoption of new information technologies and the increasing international competition in both goods and services seem to have been major sources of economic turbulence. In the case of internationalization, national economies have found themselves forced to respond to changing economic conditions in farther away places. There seems to be no slowing of the pace of this development. Instead, ongoing market liberalizations in countries such as China, India and the former centrally planned economies in Eastern Europe are accentuating the need for national economies to be flexible and responsive to changing international competition. It follows that the welfare states of today would benefit from restructuring. In designing social safety nets, it is more important than ever to incorporate incentives to work. ${ }^{14}$ Failure to do so threatens to sustain high and long-term unemployment, and needlessly to waste human capital.

\footnotetext{
14 An analysis of the optimal design of social safety nets would have to consider the question of market failures which is not present in our model of risk-neutral individuals.
} 


\section{References}

Bentolila, Samuel and Giuseppe Bertola (1990) "Firing Costs and Labour Demand: How Bad is Eurosclerosis?," Review of Economic Studies, 57, 381-402.

Blanchard, Olivier J. and Lawrence H. Summers (1986) "Hysteresis and the European Unemployment Problem," in NBER Macroeconomics Annual, 1, ed. Stanley Fischer. Cambridge, MA: MIT Press.

Dickens, William T. (1994) "Comments and Discussion," Brookings Papers on Economic Activity, 2, 262-269.

Gottschalk, Peter and Robert Moffitt (1994) "The Growth of Earnings Instability in the U.S. Labor Market," Brookings Papers on Economic Activity, 2, 217-272.

Hall, Robert E. (1982) "The Importance of Lifetime Jobs in the U.S. Economy," American Economic Review, 72, 716-724.

Harris, Richard (1993) "Globalization, Trade, and Income," Canadian Journal of Economics, 26, 755-776.

Heckman, James J. and George J. Borjas (1980) "Does Unemployment Cause Future Unemployment? Definitions, Questions and Answers from a Continuous Time Model of Heterogeneity and State Dependence," Economica, 47, 247-283.

Jackman, Richard and Richard Layard (1991) "Does Long-term Unemployment Reduce a Person's Chance of a Job? A Time-series Test," Economica, 58, 93-106.

Jacobson, Louis S., Robert J. LaLonde, and Daniel G. Sullivan (1993) "Earnings Losses of Displaced Workers," The American Economic Review, 83, 685-709.

Katz, Lawrence F. (1994) "Comments and Discussion," Brookings Papers on Economic Activity, 2, 255-261.

Layard, Richard, Stephen Nickell and Richard Jackman (1991) Unemployment: Macroeconomic Performance and the Labour Market. Oxford: Oxford University Press.

Lindbeck, Assar and Dennis J. Snower (1988) The Insider-Outsider Theory of Unemployment. Cambridge, MA: MIT Press.

Ljungqvist, Lars and Thomas J. Sargent (1995a) "Welfare States and Unemployment," Economic Theory, 6, 143-160.

Ljungqvist, Lars and Thomas J. Sargent (1995b) “The Swedish Unemployment Experience," European Economic Review, 39, 1043-1070. 
Malinvaud, Edmond (1994) Diagnosing Unemployment. Cambridge, Great Britain: Cambridge University Press.

Martin, John P. (1996) "Measures of Replacement Rates for the Purpose of International Comparisons: A Note," OECD Economic Studies, No. 26, 99-115.

Neal, Derek (1995) "Industry-Specific Human Capital: Evidence from Displaced Workers," Journal of Labor Economics, 13, 653-677.

OECD (1983) "Employment Outlook," Paris.

OECD (1984a) "Labour Force Statistics," Paris.

OECD (1984b) "Employment Outlook," Paris.

OECD (1991) "Employment Outlook," Paris.

OECD (1992a) "Employment Outlook," Paris.

OECD (1992b) "OECD Economic Surveys - Netherlands," Paris.

OECD (1993) "Employment Outlook," Paris.

OECD (1994a) "The OECD Jobs Study: Evidence and Explanations," Paris.

OECD (1994b) "The OECD Jobs Study: Facts, Analysis, Strategies," Paris.

OECD (1995) "Employment Outlook," Paris.

OECD (1996) "Employment Outlook," Paris.

Pissarides, Christopher, A. (1992) "Loss of Skill during Unemployment and the Persistence of Employment Shocks," Quarterly Journal of Economics, 107, 1371-1391.

Sinfield, Adrian (1968) The Long-Term Unemployed: A Comparative Survey, Employment of Special Groups, No. 5, OECD, Paris. : .

Topel, Robert (1991) "Specific Capital, Mobility and Wages: Wages Rise with Job Seniority," Journal of Political Economy, 99, 145-176. 